\title{
Coaxial Double-Pigtail Stent Placement: A Simple Solution to Decrease Bleeding Risk Associated With Lumen-Apposing Metal Stent?
}

\author{
Shehroz Aslam ${ }^{1}$, Zaid Ansari ${ }^{1}$, Mustafa Alani ${ }^{2}$, Indu Srinivasan ${ }^{3,} 4$, Keng-Yu Chuang 3, 4 \\ 1. Internal Medicine, Creighton University School of Medicine, St. Joseph's Hospital and Medical Center, Phoenix, USA \\ 2. Gastroenterology, Creighton University School of Medicine, St. Joseph's Hospital and Medical Center, Phoenix, USA \\ 3. Gastroenterology, Valleywise Health Medical Center, Phoenix, USA 4. Gastroenterology, Creighton University School \\ of Medicine, Phoenix, USA
}

Corresponding author: Shehroz Aslam, shehroz.aslammd@outlook.com

\begin{abstract}
Endoscopic cystogastrostomy using lumen-apposing metal stent (LAMS) is considered the first-line therapy for symptomatic pancreatic fluid collections (PFCs). Routine coaxial placement of a double-pigtail stent (DPS) through LAMS is debated. We report the case of a patient with delayed massive gastrointestinal bleed eight weeks after LAMS placement due to splenic artery pseudoaneurysm leading to a complicated hospitalization. Theoretically, coaxial placement of DPS through LAMS can prevent the relatively sharp LAMS from eroding into the mucosa of the collapsed cavity of PFCs, decreasing the risk of bleeding. Our case adds to the growing need to further explore the utility of this combined intervention.
\end{abstract}

Categories: Internal Medicine, Gastroenterology

Keywords: pancreatic fluid collections, cystogastrostomy, gastrointestinal hemorrhage, pseudoaneurysm, lams

\section{Introduction}

Pancreatic fluid collections (PFCs) are frequent complications of acute as well as chronic pancreatitis and include pancreatic pseudocyst and walled-off necrosis (WON) [1]. Most of the PFCs resolve spontaneously; however, in some cases, when left untreated they can increase in size resulting in persistent abdominal pain, infection, and biliary obstruction [2]. In these cases, non-surgical interventions for cyst drainage are preferred over surgical procedures. Cystogastrostomy through endoscopic ultrasound (EUS) has gained significant importance in the management of symptomatic pancreatic pseudocyst and WON [3]. The use of lumen-apposing metal stent (LAMS) and double-pigtail stent (DPS) has been studied for this procedure. Before the development of LAMS, DPSs were extensively used but their narrow diameters limit the drainage of solid necrotic debris; this limitation was overcome with the larger-diameter LAMS. Additionally, LAMS allows endoscopic necrosectomy through the stent lumen. LAMS, however, is associated with bleeding and stent migration $[4,5]$. Coaxial placement of DPS through LAMS has been mentioned in the literature with a goal to reduce the bleeding risk but outcome data remain sparse. We report a case of an elderly male who presented to our facility with a massive gastrointestinal (GI) bleed following LAMS placement for WON and

Review began 06/04/2021 Review ended 06/20/2021 Published 06/28/2021

\section{() Copyright 2021}

Aslam et al. This is an open access article distributed under the terms of the Creative Commons Attribution License CC-BY 4.0., which permits unrestricted use, distribution, and reproduction in any medium, provided the original author and source are credited. found to have a splenic artery pseudoaneurysm requiring surgical intervention.

\section{Case Presentation}

A 72-year-old male with a history of chronic pancreatitis and WON (measuring $6 \times 4 \times 5 \mathrm{~cm}$ ) presented to our facility with hematemesis. Eight weeks before the presentation, he underwent cystogastrostomy with necrosectomy and LAMS (AXIOS ${ }^{\mathrm{TM}}$, Boston Scientific, MA, USA) placement at an outside hospital. On presentation, his vital signs were stable with a normal physical examination. His hemoglobin (Hgb) was 9.3 gram/deciliter (g/dL), down from his baseline of $11 \mathrm{~g} / \mathrm{dL}$. Esophagogastroduodenoscopy (EGD) was performed, which showed slow oozing from the cystogastrostomy site and a large blood clot within the LAMS (Figure 1). A computed tomography angiography (CTA) performed did not demonstrate bleeding near the cystogastrostomy site but active contrast extravasation into the rectum via the inferior mesenteric artery (IMA) was noted. A branch of the IMA was then super-selectively embolized by interventional radiology (IR). The next day, patient had a 2-g drop in Hgb and a second-look EGD showed a stable clot within the LAMS without bleeding, the stent was removed, and the cavity was inspected carefully. No stigmata of recent bleed were seen within the cavity (Figures 2, 3). A colonoscopy also was performed, which was unremarkable. Roughly $1 \mathrm{~h}$ after the procedure, the patient had massive hematemesis resulting in hemorrhagic shock. A third EGD showed active bleeding from the cystogastrostomy site with very limited endoscopic visualization. The patient was taken for an exploratory laparotomy by general surgery where a small incidental gastric perforation was identified in the gastric body near the cystogastrostomy site. The perforation was repaired along with surgical closure of the cystogastrostomy. Post-operatively the patient had a good recovery and was discharged. 


\section{Cureus}

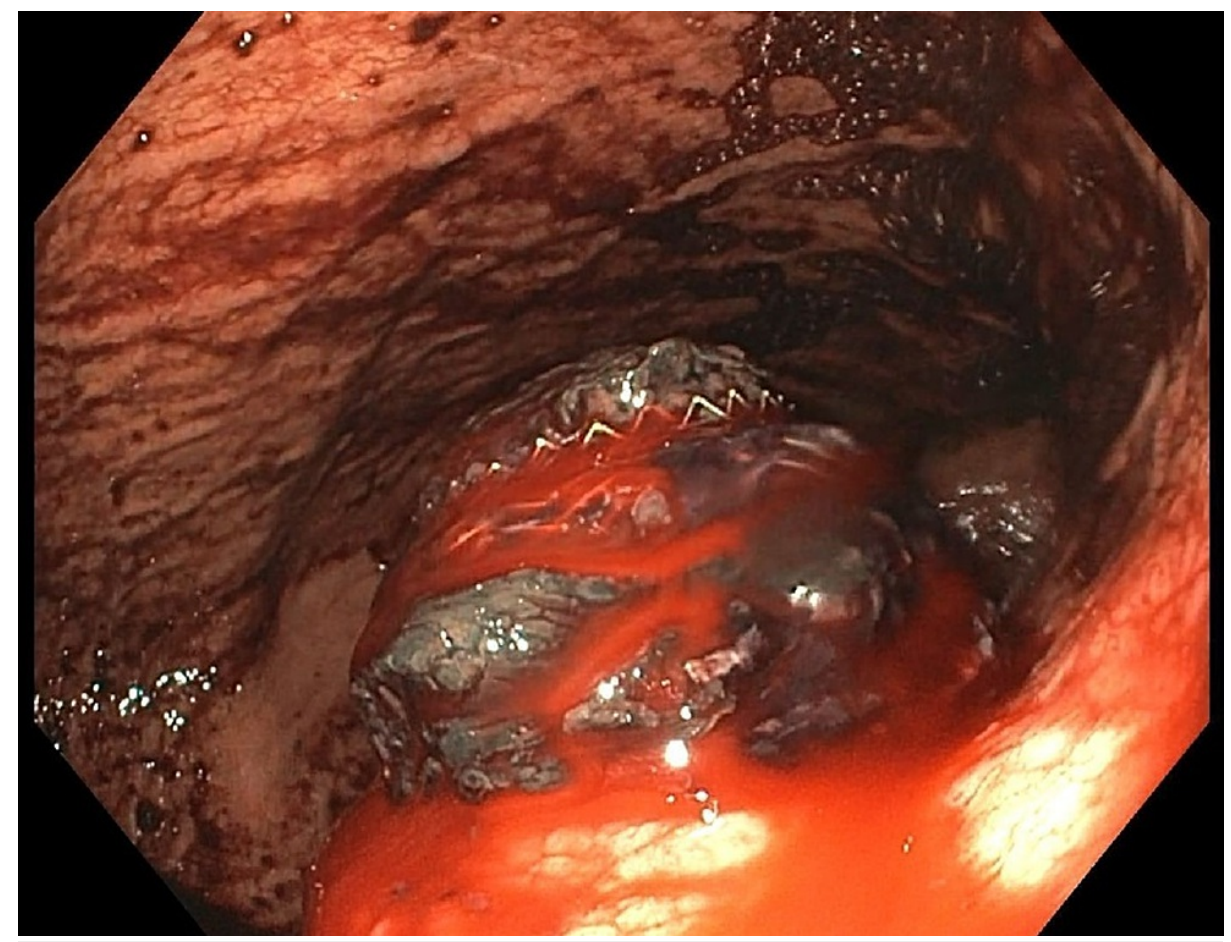

FIGURE 1: Slow oozing of blood noted around the stent

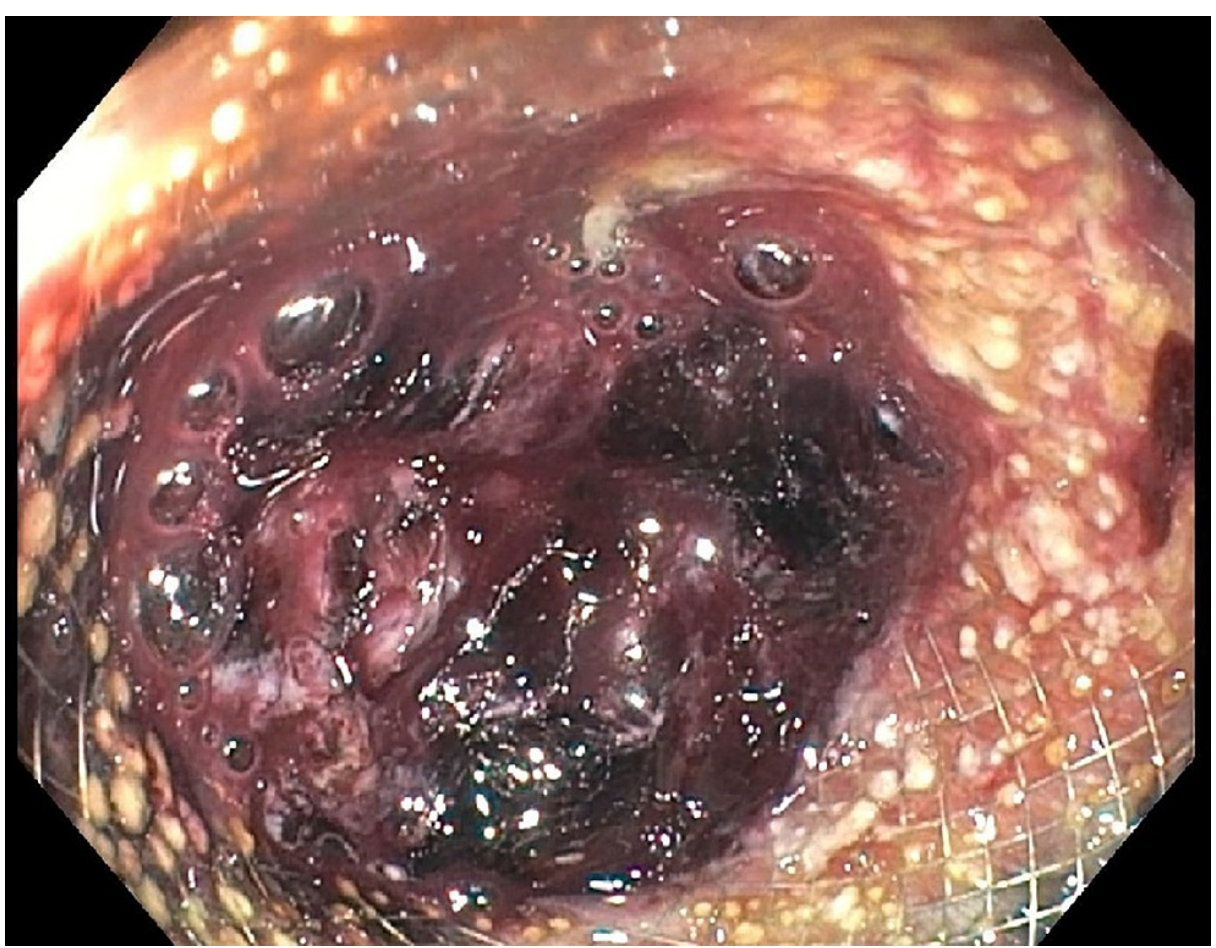

FIGURE 2: Second-look endoscopy revealing blood clots in the stent with no active bleeding 


\section{Cureus}

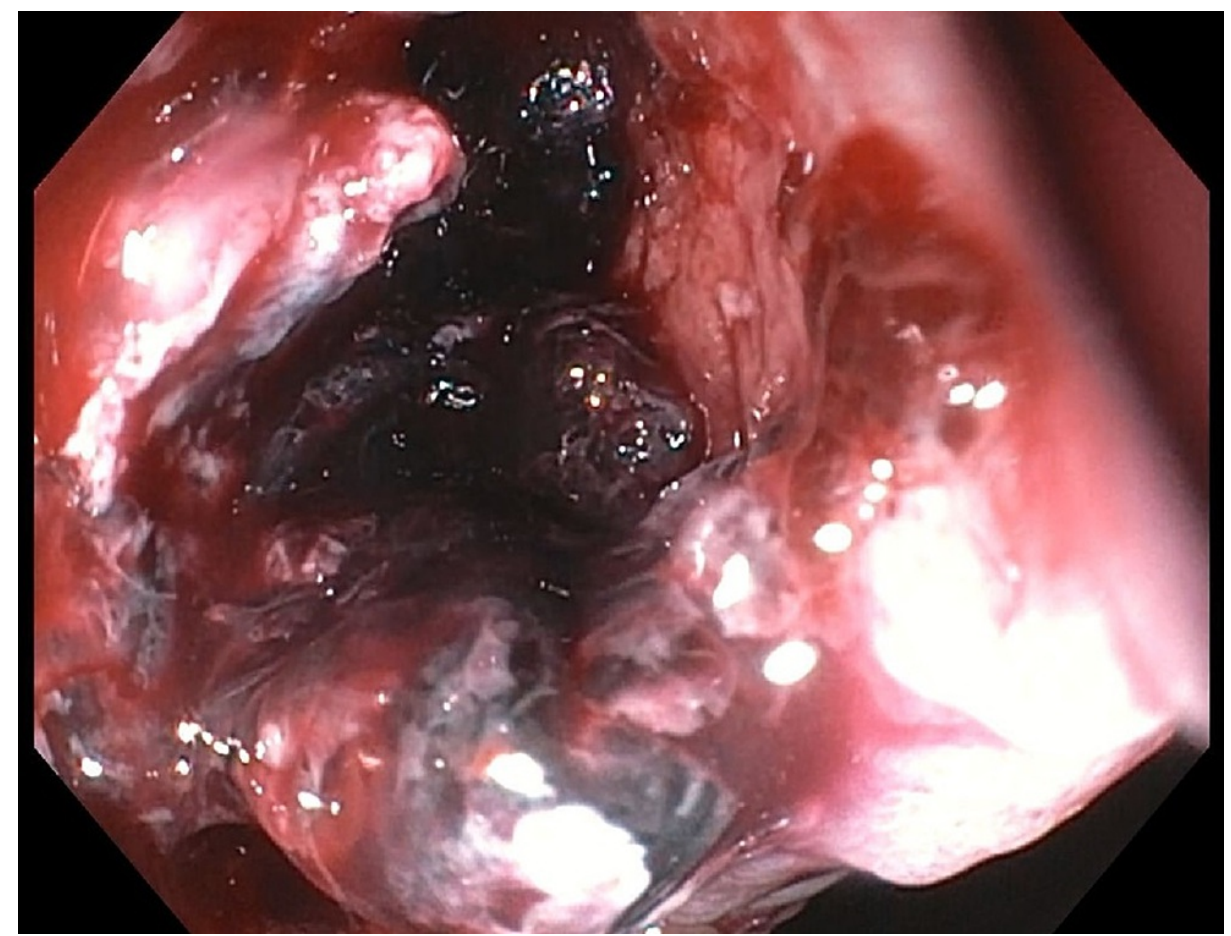

\section{FIGURE 3: Stent removed and revealed no active bleeding within the}

cystogastrostomy cavity

Three days later, he returned to the hospital with another episode of hematemesis with hemodynamic instability. CTA was again obtained, and this time a splenic artery pseudoaneurysm $(3.6 \times 1.8 \times 1.4 \mathrm{~cm})$ with active bleeding was identified, which was embolized by IR (Figures 4, 5). He, however, had another massive hematemesis $72 \mathrm{~h}$ later. A bedside EGD was attempted but failed to achieve hemostasis due to poor visualization. He was taken for another exploratory laparotomy, which revealed active bleed from the splenic artery pseudoaneurysm. This was managed with surgical ligation of the splenic artery, splenectomy, and partial gastrectomy. Reconstructive Roux-en-Y gastrojejunostomy was performed a week later. 


\section{Cureus}

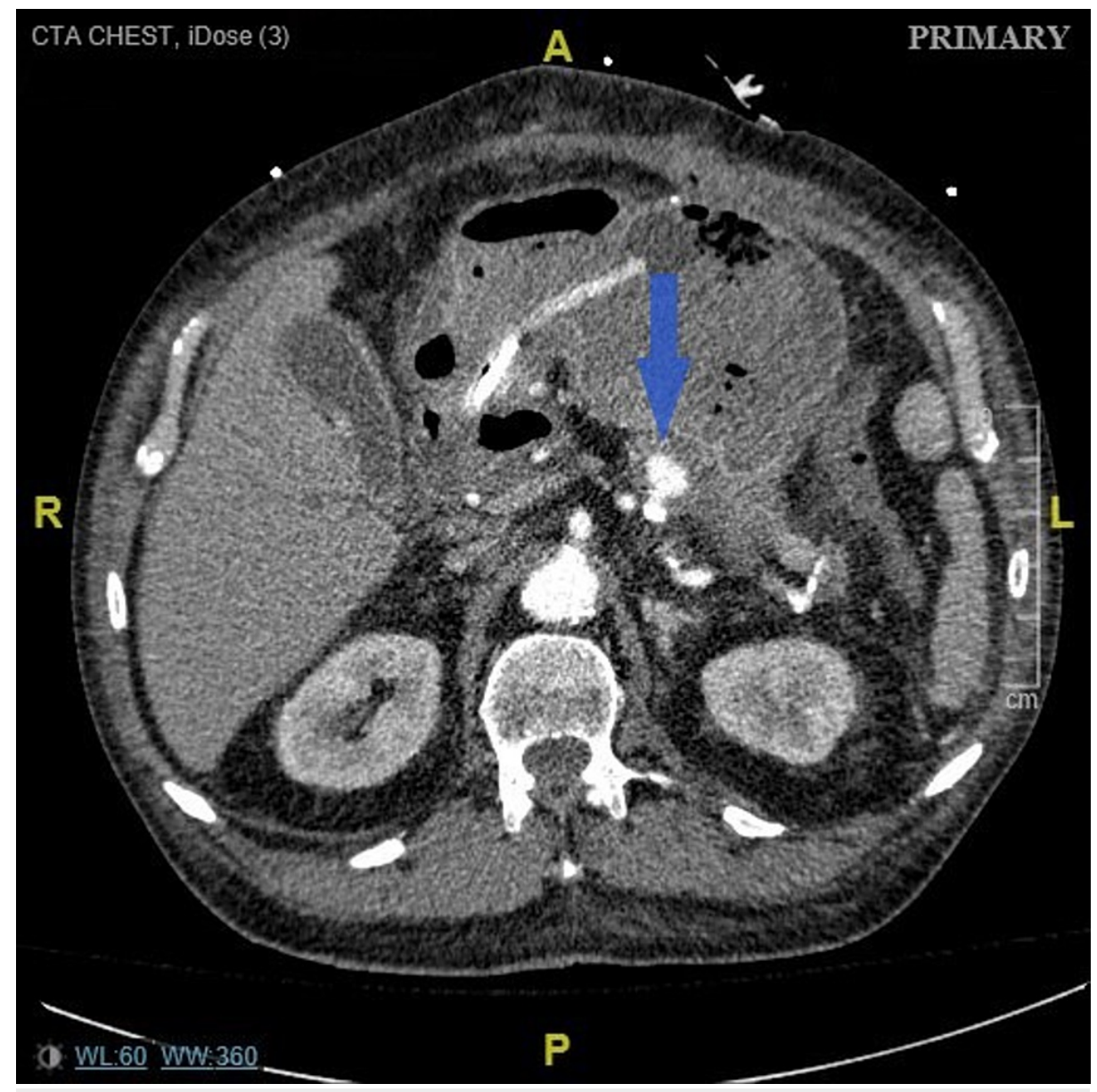

FIGURE 4: Computed tomography angiography showing splenic artery pseudoaneurysm measuring $3.6 \times 1.8 \times 1.4 \mathrm{~cm}$ (blue arrow) 


\section{Cureus}

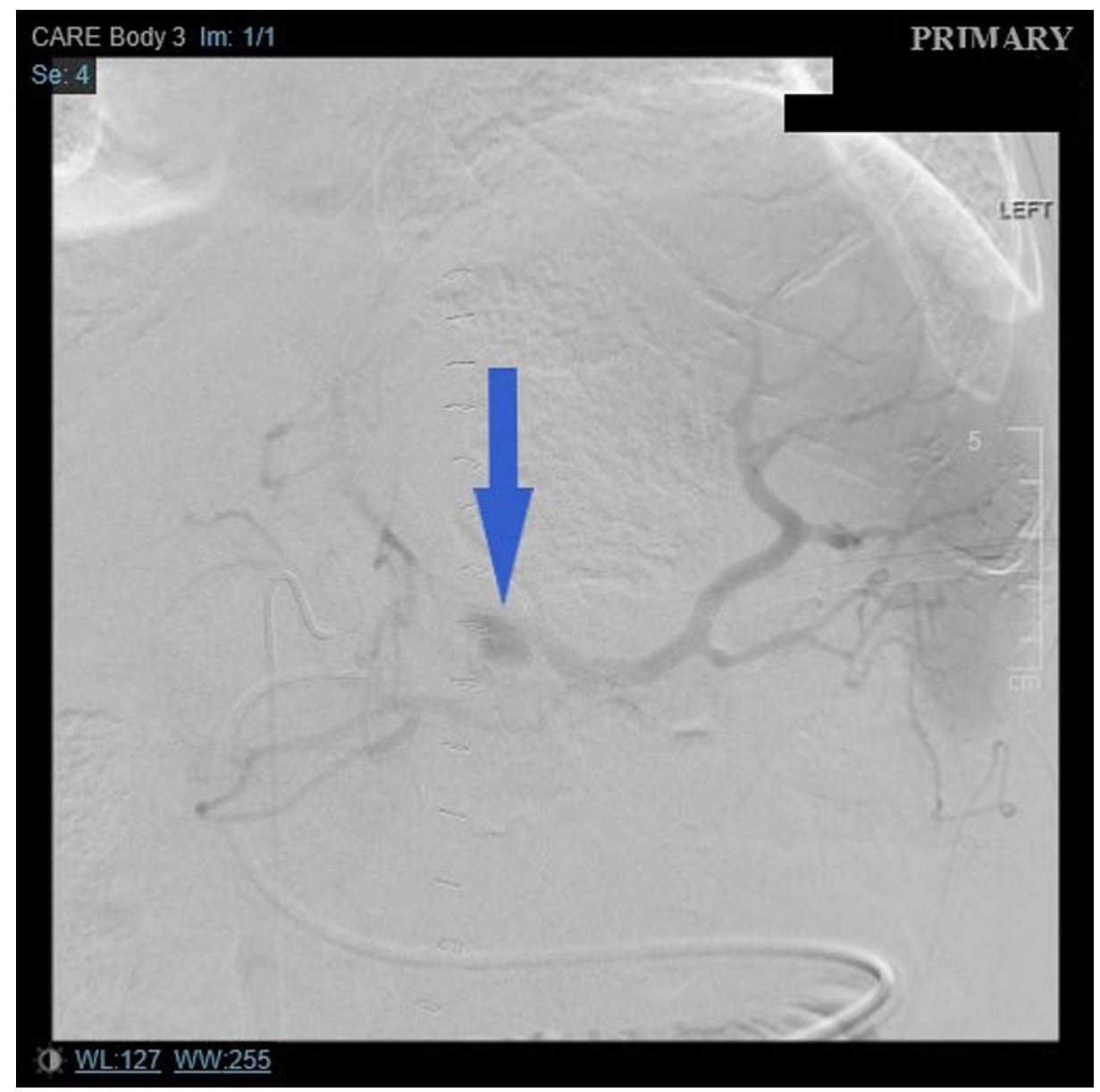

\section{FIGURE 5: Interventional radiology image of mid splenic artery pseudoaneurysm (blue arrow)}

Post-operatively the patient had a protracted hospital course on his way to recovery. No further GI bleeding was noted during the remaining hospital stay. He was eventually discharged home with close outpatient follow-up.

\section{Discussion}

EUS-guided cystogastrostomy has emerged as the gold standard for the management of PFCs [6,7]. Plastic stents in the double-pigtail configuration were initially preferred as they prevented migration; their narrow lumen, however, can lead to premature stent occlusion in up to $18 \%$ of cases, resulting in frequent stent exchanges or placement of additional stents [8,9]. Recently developed LAMS in the "dumbbell" configuration with two large flanges can minimize stent migration. The larger diameter of LAMS also allows endoscopic necrosectomy in repeated sessions without the need for stent replacement [4].

In a review, Patil et al. reported a 97\% technical success rate and a 96\% clinical success in 298 patients undergoing EUS-guided LAMS placement [10]. While LAMS and DPS have been widely studied individually, head-to-head comparisons of the two modalities are limited: an interim analysis of a randomized controlled trial by Bang et al. reported serious adverse events three weeks after the index intervention where three out of the 12 patients randomized for LAMS presented with severe GI bleeding due to a pseudoaneurysm [11]. Brimhall et al. in a retrospective analysis demonstrated comparable rates of technical and clinical success; the use of LAMS, however, was associated with a higher bleeding risk from pseudoaneurysm compared to DPS (odds ratio, 10.0; 95\% confidence interval, 1.19-84.6; $\mathrm{P}=0.009$ ) [12].

In recent years, the use of coaxial placement of DPS through LAMS to decrease bleeding complications has gained popularity (Figure 6). The placement of DPS through LAMS helps to prevent direct contact of the mucosa and surrounding vessels with the relatively sharp flange of LAMS following the collapse of PFCs. A pilot study by Aburajab et al. reported a higher risk of infection and non-resolution of pancreatic pseudocyst with the use of LAMS alone. The risk, however, was decreased with the placement of DPS across LAMS (relative risk, 0.84; 95\% confidence interval, 0.71-1.0; $\mathrm{P}=0.054$ ) [13]. Another retrospective study by Puga et al. reported that LAMS alone had a significantly higher rate of adverse events compared to LAMS plus 


\section{Cureus}

coaxial DPS for drainage of PFCs ( $42.9 \%$ vs $10.0 \%$; $\mathrm{P}=0.04$ ) with bleeding being the most common adverse event [14]. Rossi et al. analyzed the efficacy of coaxial DPS placement into LAMS with a secondary aim to decrease the bleeding risk. The bleeding rate in patients with DPS was lower (5.9\%) compared to those without (15.6\%) even though the difference did not achieve statistical significance $(P=0.65)[15]$.

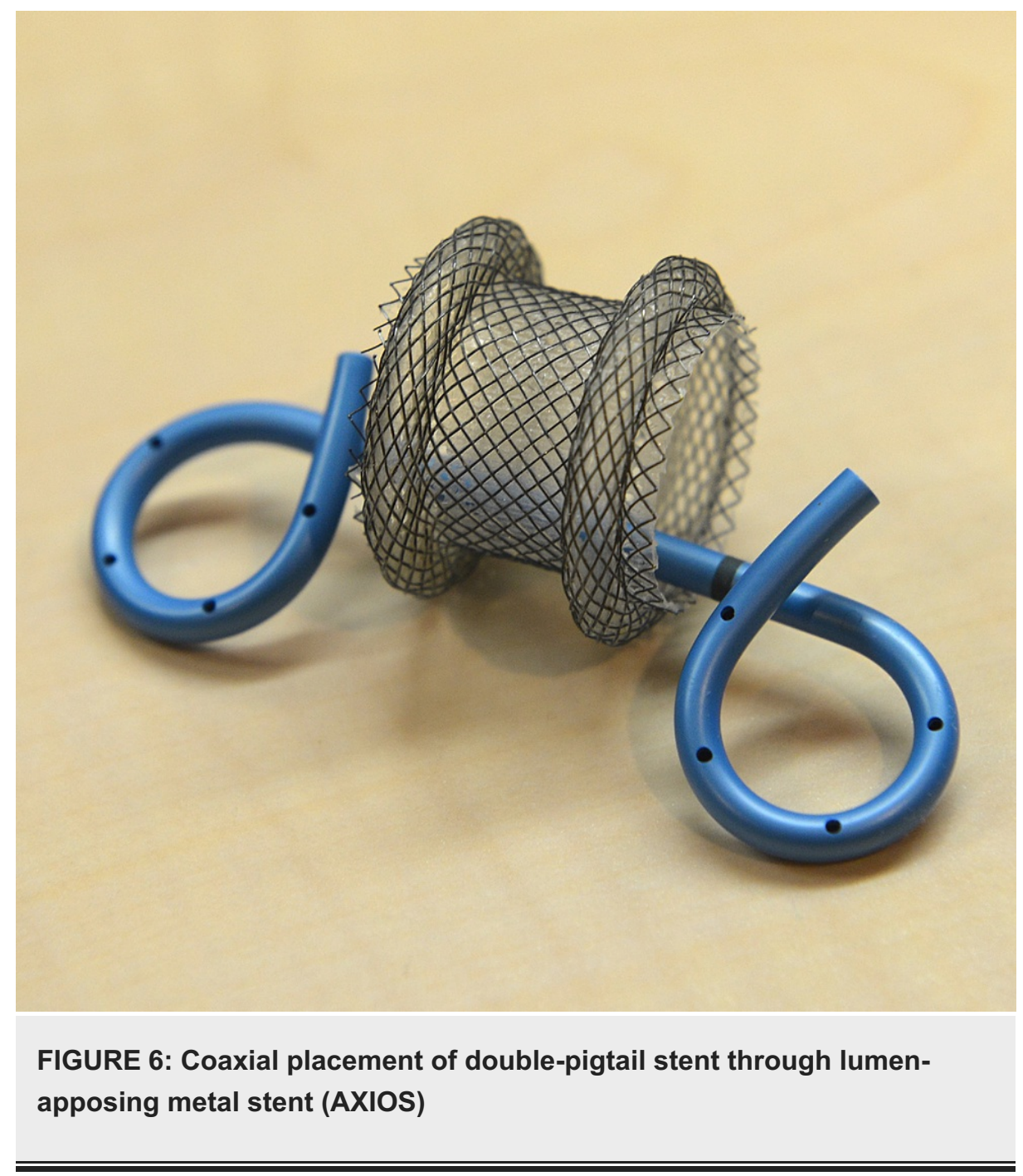

The combined use of DPS and LAMS is an ongoing topic of research. NCT03923686 is a prospective randomized trial, which is underway, analyzing the coaxial placement of DPS through LAMS for EUS-guided transmural drainage of WON [16]. The study one day might guide us to a safer use of LAMS in patients with PFCs.

\section{Conclusions}

The coaxial placement of DPS through LAMS to prevent bleeding risk remains a subject of discussion in the field of gastroenterology. We discussed a case of an elderly gentleman who presented with massive delayed splenic artery pseudoaneurysm bleeding following placement of LAMS for WON, a known complication of LAMS. This complication might have been prevented with the coaxial placement of DPS through LAMS. Based on our case we advocate for the routine use of DPS through LAMS to mitigate bleeding risks. At the same time, we encourage future randomized trials to further analyze this combined intervention.

\section{Additional Information}

\section{Disclosures}

Human subjects: Consent was obtained or waived by all participants in this study. Conflicts of interest: In compliance with the ICMJE uniform disclosure form, all authors declare the following: Payment/services info: All authors have declared that no financial support was received from any organization for the submitted work. Financial relationships: All authors have declared that they have no financial relationships at present or within the previous three years with any organizations that might have an interest in the submitted work. Other relationships: All authors have declared that there are no other relationships or activities that could appear to have influenced the submitted work. 


\section{References}

1. Banks PA, Bollen TL, Dervenis C, et al.: Classification of acute pancreatitis--2012: revision of the Atlanta classification and definitions by international consensus. Gut. 2013, 62:102-11. 10.1136/gutjnl-2012-302779

2. Brun A, Agarwal N, Pitchumoni CS: Fluid collections in and around the pancreas in acute pancreatitis . J Clin Gastroenterol. 2011, 45:614-25. 10.1097/MCG.0b013e318213ef3e

3. Sharaiha RZ, DeFilippis EM, Kedia P, et al.: Metal versus plastic for pancreatic pseudocyst drainage: clinical outcomes and success. Gastrointest Endosc. 2015, 82:822-7. 10.1016/j.gie.2015.02.035

4. Rinninella E, Kunda R, Dollhopf M, et al.: EUS-guided drainage of pancreatic fluid collections using a novel lumen-apposing metal stent on an electrocautery-enhanced delivery system: a large retrospective study (with video). Gastrointest Endosc. 2015, 82:1039-46. 10.1016/j.gie.2015.04.006

5. Itoi T, Binmoeller KF, Shah J, et al.: Clinical evaluation of a novel lumen-apposing metal stent for endosonography-guided pancreatic pseudocyst and gallbladder drainage (with videos). Gastrointest Endosc. 2012, 75:870-6. 10.1016/j.gie.2011.10.020

6. Varadarajulu S, Bang JY, Phadnis MA, Christein JD, Wilcox CM: Endoscopic transmural drainage of peripancreatic fluid collections: outcomes and predictors of treatment success in 211 consecutive patients. J Gastrointest Surg. 2011, 15:2080-8. 10.1007/s11605-011-1621-8

7. Varadarajulu S, Lopes TL, Wilcox CM, Drelichman ER, Kilgore ML, Christein JD: EUS versus surgical cystgastrostomy for management of pancreatic pseudocysts. Gastrointest Endosc. 2008, 68:649-55. 10.1016/j.gie.2008.02.057

8. Singhal S, Rotman SR, Gaidhane M, Kahaleh M: Pancreatic fluid collection drainage by endoscopic ultrasound: an update. Clin Endosc. 2013, 46:506-14. 10.5946/ce.2013.46.5.506

9. Lopes CV, Pesenti C, Bories E, Caillol F, Giovannini M: Endoscopic-ultrasound-guided endoscopic transmural drainage of pancreatic pseudocysts and abscesses. Scand J Gastroenterol. 2007, 42:524-9. 10.1080/00365520601065093

10. Patil R, Ona MA, Papafragkakis C, Anand S, Duddempudi S: Endoscopic ultrasound-guided placement of AXIOS stent for drainage of pancreatic fluid collections. Ann Gastroenterol. 2016, 29:168-73. 10.20524/aog.2016.0008

11. Bang JY, Hasan M, Navaneethan U, Hawes R, Varadarajulu S: Lumen-apposing metal stents (LAMS) for pancreatic fluid collection (PFC) drainage: may not be business as usual. Gut. 2017, 66:2054-6. 10.1136/gutjnl-2016-312812

12. Brimhall B, Han S, Tatman PD, et al.: Increased incidence of pseudoaneurysm bleeding with lumenapposing metal stents compared to double-pigtail plastic stents in patients with peripancreatic fluid collections. Clin Gastroenterol Hepatol. 2018, 16:1521-8. 10.1016/i.cgh.2018.02.021

13. Aburajab M, Smith Z, Khan A, Dua K: Safety and efficacy of lumen-apposing metal stents with and without simultaneous double-pigtail plastic stents for draining pancreatic pseudocyst. Gastrointest Endosc. 2018, 87:1248-55. 10.1016/j.gie.2017.11.033

14. Puga M, Consiglieri CF, Busquets J, et al.: Safety of lumen-apposing stent with or without coaxial plastic stent for endoscopic ultrasound-guided drainage of pancreatic fluid collections: a retrospective study. Endoscopy. 2018, 50:1022-6. 10.1055/a-0582-9127

15. Rossi G, Capurso G, Petrone MC, et al.: Does co-axial plastic double pig tail stent placement into lumenapposing metal stents reduce risks in EUS-guided drainage of pancreatic fluid collections. Endoscopy. 2019, 51:169. 10.1055/s-0039-1681345

16. Lumen-apposing Metal Stent With or Without Coaxial Plastic Stent for Treatment of Walled-off Pancreatic Necrosis. (2019). Accessed: February 2, 2021: https://ClinicalTrials.gov/show/NCT03923686. 